\title{
Editor introduction
}

\author{
Lori M. Hunter
}

Published online: 20 March 2010

(C) Springer Science+Business Media, LLC 2010

This issue of Population and Environment begins to fill gaps. As in other recent journal issues, the manuscripts here represent innovations in topic and in method, new questions are asked and new sources of data are employed. This collection advances knowledge on techniques to measure air pollution, and to link hazard vulnerability and recovery. New questions are asked regarding the fertility implications of natural disasters, and the environmental implications of Israeli demographic dynamics.

First, Finch, Emrich, and Cutter build upon history. In 2005, the world watched in disbelief as the massive destruction wrought by Hurricane Katrina on New Orleans was widely broadcast. Yet the long process of recovery has received less public attention. In "Disaster Disparities and Differential Recovery in New Orleans," Finch and colleagues offer intriguing and important evidence of the distribution of vulnerability, and the ways in which this vulnerability has shaped New Orleans's recovery. The spotlight of charitable organizations shines most brightly on intensely vulnerable neighborhoods; Consider actor Brad Pitt's efforts at rebuilding with his organization, "Make It Right," in the Lower Ninth Ward. As illustrated through a combination of statistical and spatial analyses, Finch and colleagues reveal that recovery is now lagging in the "in-between neighborhoods" - those not poor enough to garner charitable or other support, but still too poor to recover effectively on their own. Importantly, the authors explore possible roles that government programs have played within these inequities.

Filling a gap in both knowledge and data, Emilio Gutierrez presents his research in "Using Satellite Imagery to Measure the Relationship between Air Quality and Infant Mortality: An empirical study for Mexico." The author makes use of a relatively inexpensive measure of air quality, at very detailed geography, developed through satellite imagery. This measure of aerosol optical depth (AOD) is linked

L. M. Hunter $(\square)$

University of Colorado at Boulder, Boulder, CO, USA

e-mail: lorimaehunter@comcast.net 
with infant mortality records by cause of death published by the Mexican statistical authority. The analyses reveal the anticipated positive association between air pollution and infant health, but surprising results for some Mexican regions. Gutierrez explores these surprises and offers discussion of the potential use of these data within other regions, particularly those lacking broadly based air quality indicators.

Next, Israel is a setting for which there is virtually no population-environment scholarship. Even so, there is compelling anecdotal evidence that population pressures are dramatically changing Israel's natural environment. These associations are explored by Daniel Orenstein in his article "Population and Pavement: Population Growth and Land Development in Israel." Orenstein argues that "Population issues-fertility, immigration, demographic composition and spatial distribution - have been central to Israeli public policy since before the country's establishment in 1948." He presents spatial analyses of the association between population growth and land use change within 40 localities across Israel, incorporating multiple time points. Orenstein's results reveal consistent relationships between demographic patterns and land use change, although the strength varies by spatial scale. Of particular contribution to future research, Orenstein argues that analyses at multiple scales begin to reveal intermediate factors shaping the population-environment association. He offers discussion of the ways in which these play out in Israel.

And finally, there is also virtually no scholarship linking natural disasters and fertility. Creatively using historic data from two dissimilar countries, Cynthia Lin explores this connection in her article, "Instability, Investment, Disasters, and Demography: Natural Disasters and Fertility in Italy (1820-1962) and Japan (16711965). According to Lin's results, short-run instability, particularly that arising from the natural environment, may be associated with a decrease in investment in the population size of future generations. While intellectually intriguing, such insight also holds the potential for social scientists, and those developing policy and programs, to better predict the potential effects of the increase in natural disasters that may result from global climate change.

Thank you to the contributing authors and the excellent peer reviews of their research provided by our academic community. May we all find inspiration in these creative projects as we work to fill the many remaining gaps in our understanding of the association between population dynamics and the natural environment. 